\title{
Production of Polyhydroxyalkanoate from Paenibacillus durus BV-1 Isolated from Oil Mill Soil
}

Basavaraj Hungund ${ }^{1 *}$, Shyama VS², Pallavi Patwardhan ${ }^{1}$ and Arabi Mohammed Saleh ${ }^{2}$

${ }^{1}$ Department of Biotechnology, BVB College of Engineering \& Technology, Hubli, India

${ }^{2}$ School of Bio Sciences \& Technology, VIT University, Vellore, India

\begin{abstract}
Polyhydroxyalkanoates (PHAs) are polyesters naturally synthesized by numerous bacteria as intracellular energy storage materials during unbalanced growth. These polyesters find many applications in medicine, veterinary practice, tissue engineering, food packaging, etc. In the present study, spent wash and oil mill soil samples were screened for the isolation of bacteria producing polyhydroxyalkanoates. Different bacterial isolates were screened by PCR using primers designed for Bacillus megaterium. Isolate-4 reacted positively giving amplicons similar in size to that of Bacillus megaterium. Based on 16S rRNA gene sequences, isolate- 4 was identified as Paenibacillus durus. Nitrogen limited mineral salt medium with fructose as chief carbon source was used for production of Polyhydroxybutyrate (PHB) in shake flask studies. The effect of various carbon and nitrogen sources on PHB production was evaluated, with respect to yield and PHB content. The study revealed that fructose and peptone gave better PHB accumulation and growth rates for the isolate and the reference strain, and hence, were the best among the carbon and nitrogen sources used. Further studies are needed to optimize the production conditions.
\end{abstract}

Keywords: Polyhydroxyalkanoate; Polyhydroxybutyrate; PCR; Paenibacillus durus; Carbon and nitrogen sources

\section{Introduction}

Polyhydroxyalkanoate (PHA) is one of the microbial polymers which accumulate in bacteria as intracellular storage granules, in the presence of excess carbon sources and limited nitrogen source [1]. The polymer is known to occur as intracellular granules in several genera of microorganisms under specific nutrient limitation conditions [2]. PHAs are produced as energy/carbon storage materials from various substrates, including sugars and plant oils. These granules are synthesized by prokaryotes using fatty acids, sugars, and other carbon sources [3]. Because of their inherent biodegradability, PHA are considered to be good candidates for biodegradable plastics and elastomers, since they possess material properties similar to those of synthetic polymers currently in use, and are completely biodegradable after disposal. Poly 3-hydroxybutyrate (PHB), a class of PHA is insoluble in water, resistant to ultraviolet radiation, and is impermeable to oxygen, and finds many industrial applications, including use as food packaging material. This polymer is readily degraded in the soil and sewage, and can be processed using the extrusion technology that is currently used in making polyethylene or polypropylene films [4]. The PHA content and its composition are influenced mainly by the strain of the microorganism, the type of substrate employed, its concentration, and other growth conditions [5]. To achieve a cost effective PHA production, the availability of an efficient bacterial strain is a prerequisite, and is a focus of interest for many investigations. Accumulation of PHB as hydrophobic inclusions is observed in the cytoplasm of Bacillus megaterium, and in many other Gram positive and Gram negative bacteria [6-8]. One of the major stumbling blocks in the large scale production is the high production cost. Studies have shown that the raw material costs (mainly carbon source) contribute most significantly to overall production cost [9]. Since the costs of production depend, first of all, on prices for feedstock of fermentations, it is necessary to find inexpensive suitable carbon and nitrogen sources. In this case, however, one has to take into account the fact that high yielding organisms have to tolerate relatively non-standardized raw or waste materials.
In the present study, PHB accumulating bacteria from oil mill soil were isolated, identified, and characterized. An attempt was also made to produce effective amount of PHB using different carbon and nitrogen sources in mineral salt medium. The polymer production and yield among the native isolate was compared to that of reference organism.

\section{Materials and Methods}

\section{Microorganism}

Soil samples $6.0-8.0 \mathrm{~cm}$ deep from surface was used for isolation of the bacteria. About 15-20 g of soil samples scraped with sterile spatula was placed in sterile plastic bags. Around $1.0 \mathrm{~g}$ of soil sample was serially diluted in sterile saline solution and plated onto nutrient agar plates, and incubated at $30^{\circ} \mathrm{C}$ for 48 hours. After incubation period, the plates were observed for development of different macroscopic colonies. Various colonies of different morphologies were individually picked and inoculated into nutrient broth, and allowed to grow. The bacteria from broth were streaked on to nutrient agar slants, incubated at $30^{\circ} \mathrm{C}$ for $24-48$ hours, and then stored at $4^{\circ} \mathrm{C}$ for further use.

\section{Screening the bacteria for $\mathrm{PHB}$ production}

Inoculum development was done in nutrient broth medium by culturing the organism. PHB production in shake flasks was studied using the basal mineral salt medium, with fructose as carbon source [10]. For shake flask experiments, $100 \mathrm{~mL}$ medium in $250 \mathrm{~mL}$

*Corresponding author: Basavaraj Hungund, Department of Biotechnology, BVB College of Engineering \& Technology, Hubli, India, Tel: +91-9449169349; Fax: +91-836-2374985; E-mail: bshungund@bvb.edu

Received November 30, 2012; Accepted December 28, 2012; Published December 29, 2012

Citation: Hungund B, Shyama VS, Patwardhan P, Saleh AM (2013) Production of Polyhydroxyalkanoate from Paenibacillus durus BV-1 Isolated from Oil Mill Soil. J Microb Biochem Technol 5: 013-017. doi:10.4172/1948-5948.1000092

Copyright: (C) 2013 Hungund B, et al. This is an open-access article distributed under the terms of the Creative Commons Attribution License, which permits unrestricted use, distribution, and reproduction in any medium, provided the original author and source are credited 
Erlenmeyer flasks were sterilized by autoclaving ( $15 \mathrm{lb}, 20$ minutes) and cooled. They were inoculated with $1.0 \%(\mathrm{v} / \mathrm{v})$ inoculum of overnight culture, and incubated at $37^{\circ} \mathrm{C}$ at $120 \mathrm{rpm}$ for 48 hours. The bacteria were screened for PHB granule accumulation from 16 hours onwards, using Sudan black B staining methods. The bacteria positive for PHB production were selected by observing granules under phase contrast microscope (LaboMed LX-400). Bacterial cultures showing substantial granules were selected for further study.

\section{Molecular biology procedures}

Bacterial culture was grown in $5 \mathrm{~mL}$ of sterile nutrient broth for 24 hours at $30^{\circ} \mathrm{C}$ in a shaker incubator. The cells were harvested by centrifugation $(6,000 \mathrm{rpm}$ for 10 minutes). The supernatant was discarded and pellet was treated with Proteinase $\mathrm{K}$, at a concentration of $100 \mu \mathrm{g} / \mathrm{ml}$ at $37^{\circ} \mathrm{C}$ for 30 minutes. A $500 \mu \mathrm{L}$ of $4 \mathrm{M}$ Guanidium iso thiocyanate solution was added and mixed well. The vials were centrifuged at $10,000 \mathrm{rpm}$ for 10 minutes. The supernatant was decanted carefully into the fresh vial. To this preparation, $0.5 \mathrm{~mL}$ of isopropanol was added, and mixed well. The vials were centrifuged at $10,000 \mathrm{rpm}$ for 10 minutes. The supernatant was discarded and the pellet dried thoroughly. The dried pellet was suspended in $100 \mu \mathrm{L}$ of $1 \mathrm{X}$ TE buffer (10 mM Tris-Cl and $1 \mathrm{mM}$ EDTA, pH 8) $10 \mu \mathrm{g} / \mathrm{mL}$ of RNase was added, and incubated $42^{\circ} \mathrm{C}$ for 20 minutes. Equal volumes of phenol:Chloroform:Isoamyl alcohol (25:24:1) was added, and mixed well. The vials were centrifuged at $8,000 \mathrm{rpm}$ for 10 minutes. The aqueous layer was pipette out into fresh vial. Equal volumes of isopropanol and $0.3 \mathrm{M}$ Sodium acetate was added, and mixed well. The vials were again centrifuged at $10,000 \mathrm{rpm}$ for 10 minutes. The supernatant was discarded and the pellet was dried thoroughly. The dried pellet was suspended in $50 \mu \mathrm{L}$ of $1 \mathrm{X}$ TE buffer. A known volume $(5 \mu \mathrm{L})$ from this sample was loaded on to agarose gel for quantification. The following components were added into PCR vial: sterile water (38 $\mu \mathrm{L}), 10 \mathrm{X}$ Taq Pol assay buffer $(5 \mu \mathrm{L}), 10 \mathrm{mM}$ dNTP mix $(2 \mu \mathrm{L})$, forward primer $(1 \mu \mathrm{L})$, reverse primer $(1 \mu \mathrm{L})$, Taq polymerase $(1 \mu \mathrm{L})$, template $(2 \mu \mathrm{L})$, to make total volume $50 \mu \mathrm{L}$ for one reaction. Amplification was carried out using genomic DNA $(1 \mu \mathrm{L})$ as template and B1F: B2R set of primers. The thermal cycle program run on PCR (Thermocycler, Eppendorf) consisted of one cycle at $94^{\circ} \mathrm{C}$ for 2 minutes and 35 cycles of $94^{\circ} \mathrm{C}$ for 0.5 minutes, $52^{\circ} \mathrm{C}$ for 1 minute, $72^{\circ} \mathrm{C}$ for 1.5 minute, followed by incubation at $72^{\circ} \mathrm{C}$ for 10 minutes. PCR products were analyzed by gel electrophoresis in agarose gels. The amplified DNA fragments were visualized by UV illumination, and images were captured using gel imaging system (Alpha-Innotech Corporation).

\section{Identification of isolate by $16 \mathrm{~S}$ rRNA gene}

The genomic DNA from the isolate was extracted, as per standard protocol described earlier [11]. The 16S rRNA gene amplification was carried out using Taq polymerase using Thermo cycler, Eppendorf. The amplification products were purified using PCR purification kit, according to the manufacturer's instruction, with elution in $50 \mu \mathrm{l}$ of PCR water. The purified PCR products were sequenced by Aristogene Biosciences, Bangalore, India. The 16S rRNA gene sequence analysis was carried out using NCBI-BLAST program. The 16S rRNA gene sequence of one isolate was analyzed using multiple sequence alignments generated by CLUSTAL W program [12]. Phylograms were constructed using neighbor-joining analysis.

\section{Culture medium and $\mathrm{PHB}$ production}

The production medium used was mineral salts medium which contained following ingredients $(\mathrm{g} / \mathrm{L})$ : Urea-1.0, Yeast extract-0.16,
$\mathrm{KH}_{2} \mathrm{PO}_{4}-1.52, \quad \mathrm{Na}_{2} \mathrm{HPO}_{4}-4.0, \quad \mathrm{MgSO}_{4} .7 \mathrm{H}_{2} \mathrm{O}-0.52, \quad \mathrm{CaCl}_{2}-0.02$, Fructose-40, and trace element solution $0.1 \mathrm{ml}$. Trace element solution contained (g/L): $\mathrm{ZnSO}_{4} .7 \mathrm{H}_{2} \mathrm{O}-0.13, \mathrm{FeSO}_{4} .7 \mathrm{H}_{2} \mathrm{O}-0.02,\left(\mathrm{NH}_{4}\right)_{6} \mathrm{MO}_{7} \mathrm{O}_{24}$ $4 \mathrm{H}_{2} \mathrm{O}-0.06$ and $\mathrm{H}_{3} \mathrm{BO}_{3}-0.06$. Both fructose and trace element solution were autoclaved separately, and reconstituted prior to inoculation. $\mathrm{PHB}$ production was carried out as per the procedure followed in our earlier studies [13]. For PHB production, $100 \mathrm{~mL}$ of production medium was inoculated with the organism. Inoculum was added at $5 \%(\mathrm{v} / \mathrm{v})$. All the flaks were incubated on a shaker incubator at $30^{\circ} \mathrm{C}$ for 72 hours. Samples were collected from each flask at an interval of 4 hours, and the cell biomass was measured at $600 \mathrm{~nm}$ using a spectrophotometer. The samples were then centrifuged at $10,000 \mathrm{rpm}$ at $4^{\circ} \mathrm{C}$ for 20 minutes, the supernatant was discarded, and the pellets were collected.

\section{PHB quantification}

PHB quantification was done as per the procedure followed in our earlier studies [13]. The pellet collected as above was washed with water, $100 \mu \mathrm{L}$ of acetone was added onto the pellet, and was allowed to dry, $500 \mu \mathrm{L}$ of sodium hypochlorite and chloroform were then added in 1:1 ratio, and allowed to stand for 30 minutes. It was then centrifuged at $10,000 \mathrm{rpm}$ at $4^{\circ} \mathrm{C}$ for 20 minutes. Three distinct layers were formed, the uppermost layer contained sodium hypochlorite, and the middle white layer was composed of cell debris, and the lower layer contained chloroform in which PHB was present in the dissolved form. The chloroform layer was carefully pipette out into glass bottles and the chloroform was allowed to evaporate. Concentrated sulfuric acid (8 $\mathrm{mL}$ ) was then added to the bottles, and the bottles were heated at $100^{\circ} \mathrm{C}$ for 40 minutes in a hot air oven, was allowed to cool, and the amount of crotonic acid was estimated by reading in a spectrophotometer at 235 $\mathrm{nm}$. The yield of PHB at each case was calculated in terms of crotonic acid.

\section{Results and Discussion}

\section{Isolation and screening of bacteria for PHB production}

Several bacteria isolated from soil samples were studied for PHB production. Different isolates representing different colony morphologies were picked-up randomly from the plates containing different samples for further analysis. Initial selection of organisms was based on appearance of deep stained colonies after putting Sudan Black B. Based on Sudan Black B staining and Spectrophotometric quantification, five isolates with maximum PHB accumulation were selected. Based on high PHB productivity, one best isolate was further selected and identified. Morphologically this isolate appeared as offwhite, circular, smooth, large colony. Microscopically it appeared as rod-shaped Gram positive bacillus. Five PHB producing bacterial strains were further characterized by Gram staining, morphological and biochemical tests. All the isolates were Gram positive, rod shaped, spore formers. Growth was observed over a wide range of temperatures $\left(15^{\circ} \mathrm{C}-45^{\circ} \mathrm{C}\right)$. Analysis of the $16 \mathrm{~S}$ rRNA gene sequences of isolate- 4 was performed using NCBI-BLAST (National centre for Biotechnology Information http://www.ncbi.nml.nih.gov). The complete sequences were aligned to the homologous sequence available for Paenibacillus strains. The BLAST search using the sequences showed $99 \%$ homology to other GenBank. The sequences of the $16 \mathrm{~S}$ rRNA gene of the isolated strain were deposited in the GenBank sequence. A phylogenetic tree (Figure 1) demonstrated that the isolate was the member of genus Paenibacillus. Sequence similarity calculations after neighbor joining analysis showed strong homology with other Paenibacillus strains available in the database (P.durus, P.pabuli, P.illinoisensis). Paenibacillus is a genus of facultative anaerobic, endospore forming 
bacteria, originally included in the genus Bacillus, and then reclassified [14]. Bacteria belonging to this genus have been detected in variety of environments. There has been a rapidly growing interest in Paenibacillus spp., since many were shown to have applications in agriculture, medicine and industry. PCR studies were conducted for the detection of PHB production by the isolate. Polymerase Chain Reaction was carried out with the isolate using the B1F:B2R set of primers. Figure 2 shows the PCR amplicons from DNA of the isolate. The isolate reacted positively and the amplicon size observed was identical to that obtained (about 600 bp), with DNA from Bacillus megaterium [15].

\section{Production of PHB using different carbon and nitrogen sources}

To investigate the effect of carbon sources on the production of $\mathrm{PHB}$, various carbon sources were provided at $4 \%(\mathrm{w} / \mathrm{v})$ in standard MSM medium. Figure 3 shows the time course of PHB production by the isolate with different carbon sources. The organism utilized glucose, fructose, sucrose and lactose for growth, and PHB accumulation giving highest yield with fructose after 58 hours of incubation. Figure 4 shows the growth patterns of the organism with these carbon sources. Various nitrogen sources were also screened separately to assess their effects

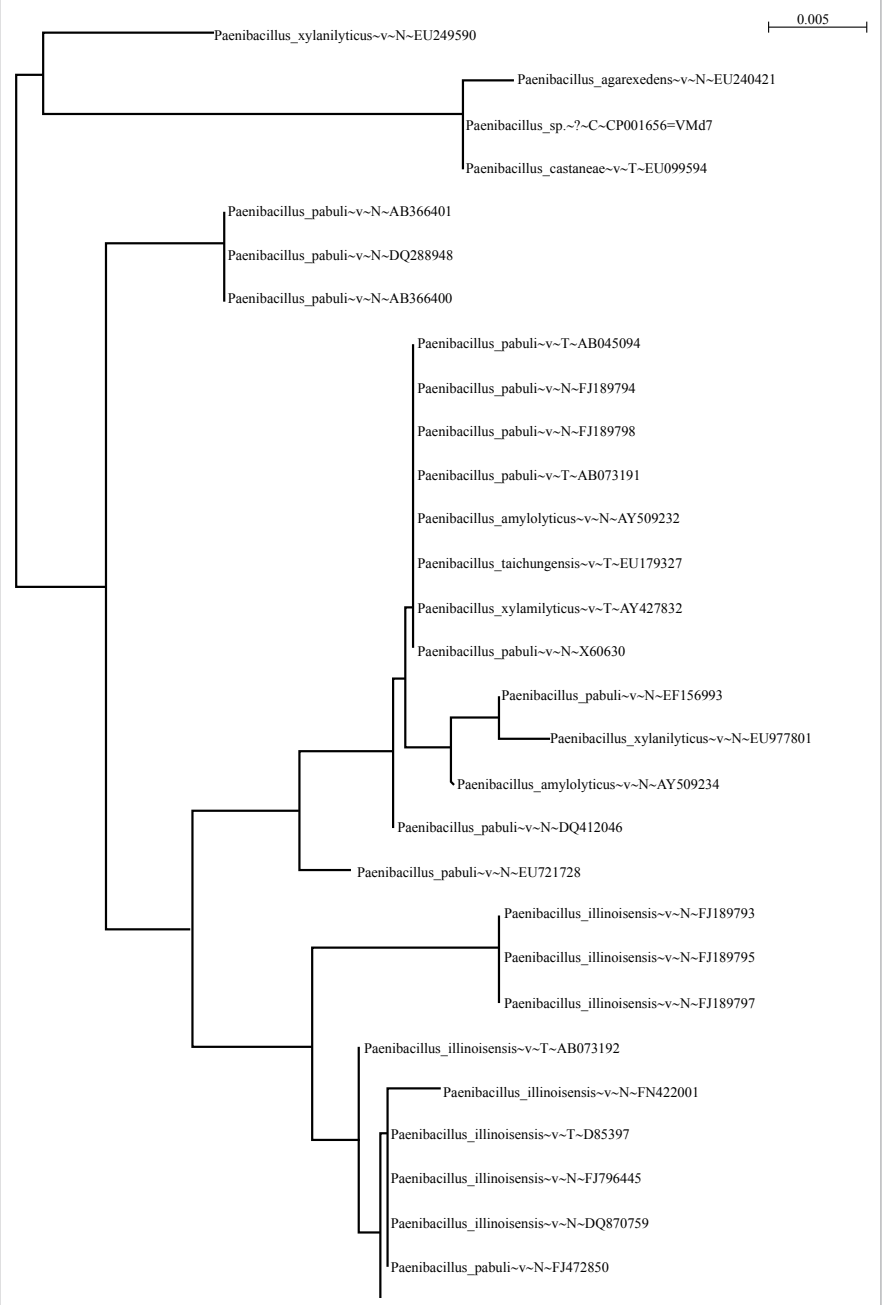

M Iso-5 Iso-4

Figure 1: Phylogenetic tree for Paenibacillus durus BV-1.

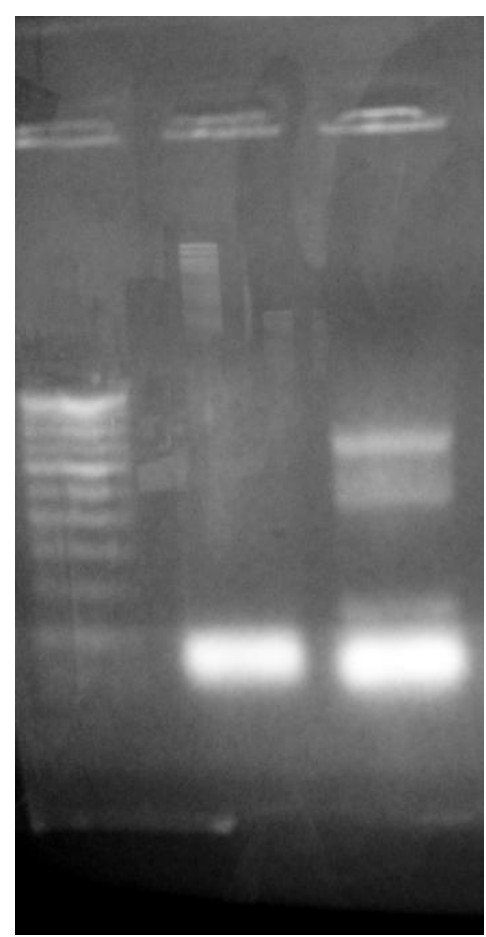

Figure 2: Polymerase Chain Reaction (PCR) amplicons from PCR using DNA from isolates and with primer (B1F:B2R). Marker-M: 100, 200, 300, 400, 500, $600,700,800,900$ and $1000 \mathrm{bp}$.

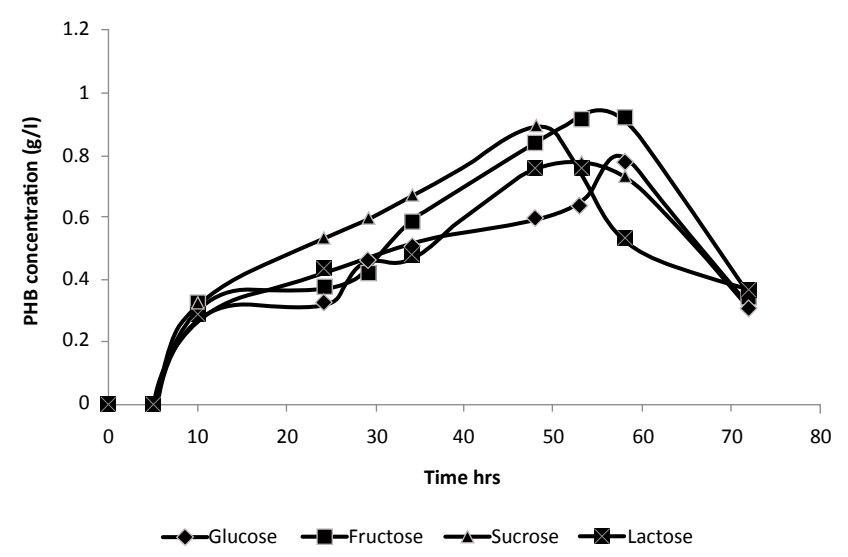

Figure 3: Time course of PHB production by Paenibacillus durus BV-1 in media with different carbon sources.

on PHB production at concentration of $1 \%(\mathrm{w} / \mathrm{v})$. Figure 5 shows the time course of $\mathrm{PHB}$ production by the isolate with different nitrogen sources. Highest PHB yield was obtained with urea as the nitrogen source. Figure 6 shows the growth patterns of the isolate with these nitrogen sources. The PHB accumulation was noticed, as early as 16 hours of incubation in the bacterial cells. The synthesis of PHB was noticed from the log phase of growth, and it continued until late exponential phase, as the carbon source was utilized for both growth and $\mathrm{PHB}$ production.

Studies on PHB production and cell growth of $P$. durus on different carbon sources were carried as a part of media optimization. As shown in figure 3, for all carbon sources, a lag phase of 10 hours was observed, 


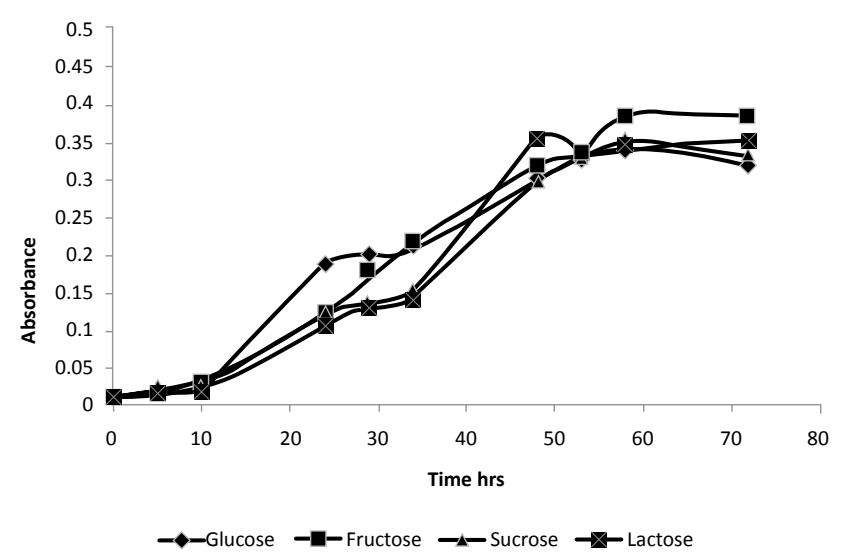

Figure 4: Growth pattern of Paenibacillus durus BV-1 in media with different carbon sources.

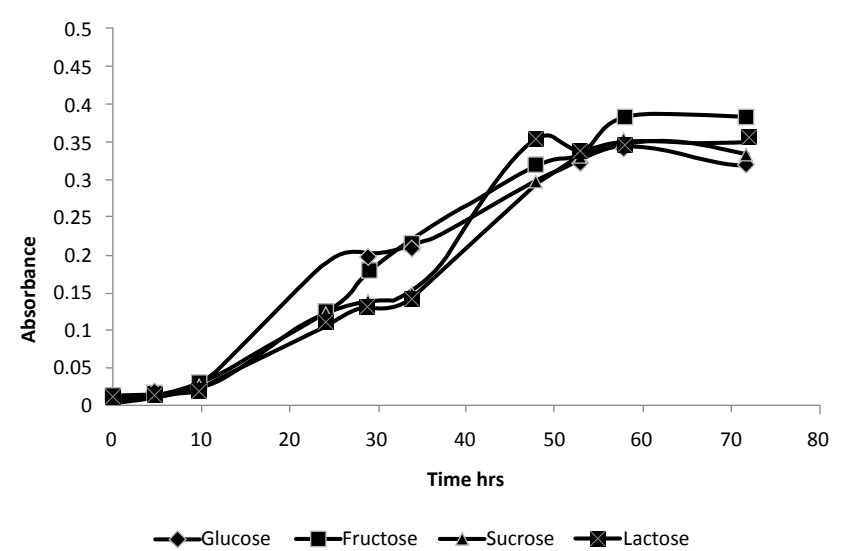

Figure 5: Time course of PHB production by Paenibacillus durus BV-1 in media with different nitrogen sources.

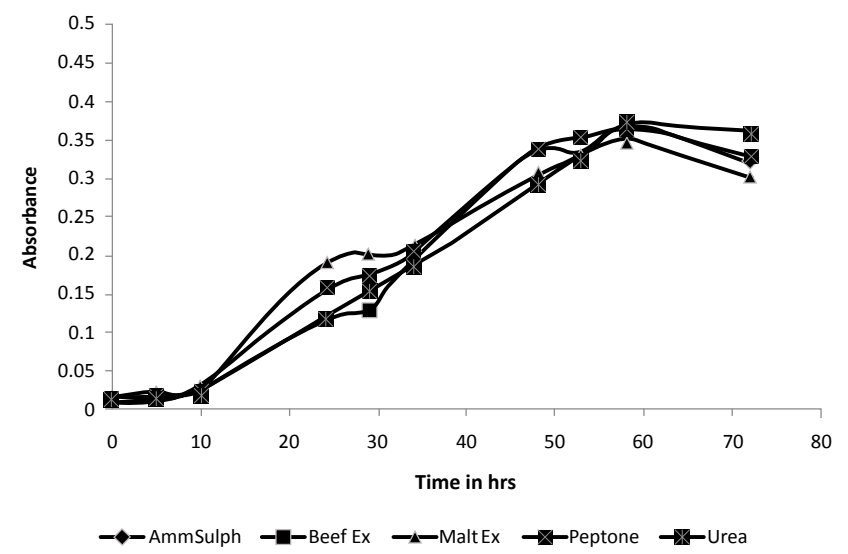

Figure 6: Growth pattern of Paenibacillus durus BV-1 in media with different nitrogen sources.

after which the culture entered the growth phase. At the end of 60 hours, the culture entered the stationary phase. PHB production was observed to be growth associated, starting at 10 hour, and reaching the highest value at end of the growth phase. The highest PHB accumulation was observed to be $0.9 \mathrm{~g} / \mathrm{l}$ for media containing fructose as carbon source, although the cell growth was comparable to the other carbon sources. This may be because fructose is a simple sugar and the most easily assimilable sugar, as compared to sucrose and lactose. In a similar study, a lag phase of 8 hours and glucose as preferred source of carbon for two isolates was demonstrated by Thirumala et al. [16] Carbon sources are crucial since they serve three different functions within the organism: biomass synthesis, cell maintenance and PHA polymerization.

A similar pattern of growth and PHB accumulation may be observed in case of studies on various nitrogen sources. The growth profiles are similar for all nitrogen sources with lag phase of 10 hours, followed by growth phase till 60 hours. PHB accumulation is observed to be growth associated. The highest PHB concentration was observed to be $0.93 \mathrm{~g} / \mathrm{L}$ for peptone. This may be because the nitrogen content of the peptone is the lowest, as compared to the other sources which may have resulted in higher $\mathrm{C} / \mathrm{N}$ ratio, and the nitrogen limitation resulted in higher PHB accumulation. Further studies on $\mathrm{C} / \mathrm{N}$ ratio and its effect on PHB formation and growth of the P. durus need to be carried out to confirm these results.

\section{Acknowledgement}

The authors acknowledge BVBCET for providing laboratory facilities. Authors also acknowledge encouragement from Principal, BVBCET, Hubli and Head of SBST, VIT Vellore.

\section{References}

1. Anderson AJ, Dawes EA (1990) Occurrence, metabolism, metabolic role, and industrial uses of bacterial polyhydroxyalkanoates. Microbiol Rev 54: 450-472.

2. Khanna S, Srivastava AK (2005) Recent advances in microbia polyhydroxyalkanoates. Process Biochem 40: 607-619.

3. Madison LL, Huisman GW (1999) Metabolic engineering of poly(3hydroxyalkanoates): from DNA to plastic. Microbiol Mol Biol Rev 63: 21-53.

4. Byrom D (1987) Polymer synthesis by microorganisms: Technology and Economics. Trends Biotechnol 5: 246-250.

5. Valappil SP, Peiris D, Langley GJ, Herniman JM, Boccaccini AR, e al. (2007) Polyhydroxyalkanoate (PHA) biosynthesis from structurally unrelated carbon sources by a newly characterized Bacillus spp. J Biotechnol 127: 475-487.

6. Brandl H, Gross RA, Lenz RW, Fuller RC (1988) Pseudomonas oleovorans as a source of poly(beta-hydroxyalkanoates) for potential applications as biodegradable polyesters. Appl Environ Microbiol 54: 1977-1982.

7. Yilmaz M, Soran H, Beyatli $Y$ (2005) Determination of poly- $\beta$-hydroxybutyrate (PHB) production by some Bacillus spp. World J Microbiol Biotechnol 21: 565566 .

8. Mukhopadhyay M, Patra A, Paul AK (2005) Production of poly(3hydroxybutyrate) and poly (3-hydroxybutyrate-co-3-hydroxy-valerate) by Rhodopseudomonas palustris SP5212. World J Microbiol Biotechnol 21: 765769.

9. Choi J, Lee SY (1997) Process analysis and economic evaluation for poly (3-hydroxybutyrate) production by fermentation. Bioprocess Engineering 17 335-342.

10. Ramsay JA, Berger E, Ramsay BA, Chavarie C (1990) Recovery of poly3-hydroxyalkanoic acid granules by a surfactant-hypochlorite treatment Biotechnology Techniques 4: 221-226.

11. Sambrook J, Fritsch EF, Maniatis T (1989) Molecular cloning. A laboratory manual. ( $2^{\text {nd }}$ edn), Cold Spring Harbor Laboratory Press, New York, USA.

12. Thompson JD, Higgins DG, Gibson TJ (1994) CLUSTAL W: improving the sensitivity of progressive multiple sequence alignment through sequence weighting, position-specific gap penalties and weight matrix choice. Nucleic Acids Res 22: 4673-4680.

13. Hungund B, Patwardhan P, Eklaspur S, Ruge M, Saptasagar V, et al. (2012 Improved production of polyhydroxybutyrate from Ralstonia eutropha. Biotechnol Bioinf Bioeng 2. 
Citation: Hungund B, Shyama VS, Patwardhan P, Saleh AM (2013) Production of Polyhydroxyalkanoate from Paenibacillus durus BV-1 Isolated from Oil Mill Soil. J Microb Biochem Technol 5: 013-017. doi:10.4172/1948-5948.1000092

14. Ash C, Priest FG, Collins MD (1993) Molecular identification of rRNA group 3 bacilli (Ash, Farrow, Wallbanks and Collins) using a PCR probe test. Proposa for the creation of a new genus Paenibacillus. Antonie Van Leeuwenhoek 64: 253-260.

15. Shamala TR, Chandrashekar A, Vijayendra SV, Kshama L (2003) Identification of polyhydroxyalkanoate (PHA)-producing Bacillus spp. using the polymerase chain reaction (PCR). J Appl Microbiol 94: 369-374.

16. Thirumala M, Reddy SV, Mahmood SK (2010) Production and characterization of PHB from two novel strains of Bacillus spp. isolated from soil and activated sludge. J Ind Microbiol Biotechnol 37: 271-278 